\title{
Optimizing Thiophosphorylation in the Presence of Competing Phosphorylation with MALDI-TOF-MS Detection
}

\author{
Laurie L. Parker ${ }^{\star}, \dagger$, Alexander B. Schilling ${ }^{\dagger}$, Stephen J. Kron ${ }^{\ddagger}$, and Stephen B. H. Kent ${ }^{\dagger}$ \\ tDepartment of Biochemistry and Molecular Biology, University of Chicago, CIS 201, 929 E. 57 th \\ Street, Chicago, Illinois 60637 \\ ${ }^{\ddagger}$ Center for Molecular Oncology, University of Chicago, Knapp R322, 924 E. 57th Street, Chicago, \\ Illinois 60637
}

\begin{abstract}
Thiophosphorylation provides a metabolically stable, chemically reactive phosphorylation analogue for analyzing the phosphoproteome in vitro and in vivo. We developed a MALDI-TOFMS based assay for optimizing thiophosphopeptide production by a kinase even in the presence of $\mathrm{Mg}^{2+}$ and ATP. We found that Abl kinase thiophosphorylation rates can be 'rescued' using $\mathrm{Mn}^{2+}$ in the presence of $\mathrm{Mg}^{2+}$. Under our ideal conditions, titration of $\mathrm{Mn}^{2+}$ and $\mathrm{ATP} / \mathrm{S}$ in the presence of $\mathrm{Mg}^{2+}$ allowed relatively rapid, highly specific thiophosphorylation by Abl tyrosine kinase, both as purified enzyme and in complex cell extracts.
\end{abstract}

\section{Keywords}

thiophosphorylation; MALDI-TOF-MS; kinase activity; Bcr-Abl; phosphoproteomics

\section{Introduction}

Phosphate transfer is a major mechanism for cellular signaling, and is the subject of a wide body of research in the field of proteomics. ${ }^{1}$ Thiophosphorylation offers a metabolically stable, chemically reactive phosphorylation analogue for investigating kinase activity in vitro and in vivo. ${ }^{2-6}$ This technique provides a number of potential advantages for detecting phosphorylation signals in vivo. For example, the phosphatase resistance of thiophosphoproteins ${ }^{7,8}$ may advantageously allow transient cellular signaling species to accumulate to detectable levels, facilitating analysis of low-level signaling events. Thiophosphate also provides a chemoselectively reactive handle for functionalization of thiophosphorylated peptides and proteins, aiding in pull-down of these molecules from complex solutions. ${ }^{3,6}$ For example, recently Shokat and co-workers used a combination of a bulky ATP $\gamma \mathrm{S}$ and a mutant kinase for specific thiophosphorylation and labeling of the substrates of that kinase. ${ }^{5}$ Additionally, the ability to chemically distinguish between

\footnotetext{
*To whom correspondence should be addressed. Tel: (773) 834-9989. Fax: (773) 702-0439. 1parker@uchicago.edu. .

Supporting Information Available: Additional graphs from sample analysis, peptide synthesis/characterization details. This material is available free of charge via the Internet at http://www.pubs.acs.org.
} 
existing phosphorylation patterns and recently thiophosphorylated molecules may lead to more informative time-resolution for studying the kinetics of in vivo signaling.

Thiophosphorylation is typically detected using $\mathrm{S}^{35}$-labeled ATP $/ \mathrm{S}$ or by reacting the phosphorothioate with e.g., fluorescent probes. ${ }^{2-4,6,9}$ The $\mathrm{p} K_{\mathrm{a}}$ of the phosphorothioate allows selective labeling at low $\mathrm{pH}$ even in the presence of cysteines and other nucleophilic residues in a peptide or protein. ${ }^{3}$ One of the challenges of using this tool is the poor competition of ATP $/ S$ against ATP, with $\mathrm{Mg}^{2+}$ as a kinase cofactor. Unfortunately, many kinases (especially tyrosine kinases) show sluggish kinetics with ATP $\gamma \mathrm{S}$ : consequently, observing 'real' kinase activity and generating enough sample for practical use can be difficult. Rate differences between phosphate and thiophosphate transfer are typically described as the 'thio-effect' by comparing the $k_{\text {cat }}$ values for phosphate vs thiophosphate transfer. ${ }^{10,11}$ Catalysis of thiophosphate transfer with $\mathrm{Mg}^{2+}$ as cofactor is often inefficient, resulting in large thio-effects. Alternative divalent metals such as $\mathrm{Mn}^{2+}$ and $\mathrm{Co}^{2+}$ can improve the efficiency of thiophosphorylation vs phosphorylation-these metals are thought to improve the activation of the terminal thiophosphate of ATP $/ \mathrm{S}$ for transfer to the substrate via chelation with the thiol (which is poorly chelated by the 'hard' ion $\mathrm{Mg}^{2+}$ ). ${ }^{10-12}$ However, kinetics of thiophosphorylation are often still very slow under these conditions. Additionally, in vitro optimization of the thio-effect does not address the issue of achieving thiophosphorylation in vivo, where competition between ATP and ATP $\gamma \mathrm{S}$ in the presence of $\mathrm{Mg}^{2+}$ remains a major challenge.

MALDI-TOF mass spectrometry has been used as a detection method for kinase assays in vitro. ${ }^{13-16}$ These nonradioactive assays allow for the direct detection of phosphorylation of peptide substrates, and result in qualitative determination of phosphorylation. However, quantification of product yields based on the ratios of peptide to phospho-peptide peak areas must be carefully calibrated due to the inherent differences in ionization efficiency of phosphorylated, thiophosphorylated and unmodified peptides.

In this work, we have developed a MALDI-TOF mass spectrometry based assay for optimizing the level of thiophosphopeptide production by a kinase even in the presence of $\mathrm{Mg}^{2+}$ and ATP. Mass spectrometry detection of thiophosphovs phosphopeptides revealed that for Abl kinase, ATP $\mathcal{S}$ utilization efficiency could be rescued by adding relatively low levels of $\mathrm{Mn}^{2+}$ in the presence of $\mathrm{Mg}^{2+}$ and ATP. Titration of $\mathrm{Mn}^{2+}$ and ATP/S allowed relatively rapid, highly specific thiophosphorylation by Abl tyrosine kinases, both as purified enzymes and in complex K562 human chronic myeloid leukemia cell extracts. The assay for optimal thiophosphorylation conditions was also demonstrated for PKA, revealing $\mathrm{Co}^{2+}$ as the best divalent cation for ensuring high thiophosphorylation levels in the presence of ATP for this serine/threonine kinase.

\section{Experimental Section}

PKA kinase (active domain) and biotinylated PKA substrate peptide were obtained from Calbiochem. Biotinylated PKA substrate peptide was obtained from Calbiochem. The StrepII-tagged Abl substrate peptide was synthesized using Boc SPPS and purified on a Waters PrepLC 4000 system (RP-C18 column). The synthesized peptide was characterized 
using LC/MS (Agilent 1100 series LC/MSD Trap). Assay analyses were performed with the Applied Biosystems Voyager 4700 MALDI-TOF/TOF mass spectrometer.

\section{Solution Phase Assay}

Assay was performed in 96-well plate format in a total volume of $30 \mu \mathrm{L}$. The kinase reaction buffer was composed of $50 \mathrm{mM}$ Tris- $\mathrm{HCl}$ (pH 7.5), $30 \mu \mathrm{g} / \mu \mathrm{L}$ BSA and $1 \mathrm{mM}$ DTT. Peptide concentration was $100 \mu \mathrm{M}$ ( $3 \mathrm{nmol}$ total). Metal cofactors and ATP and/or ATP $/ \mathrm{S}$ were added as specified. $0.34 \mu \mathrm{g}(10 \mathrm{pmol})$ of Abl (recombinantly produced kinase domain, 34 $\mathrm{kDa}$ ) was used for each well. Reactions were performed at $30{ }^{\circ} \mathrm{C}$ for $30 \mathrm{~min}$ then quenched with $10 \mu \mathrm{L}$ EDTA ( $0.5 \mathrm{M}, \mathrm{pH} 8.5)$. The resulting solutions were transferred to $5 \mu \mathrm{L}$ Streptactin-sepharose beads (IBA) pre-aliquoted into a 96-well filter bottom plate (Millipore) and allowed to equilibrate at RT for $15 \mathrm{~min}$ to bind peptide to beads. Beads were then washed on a vacuum manifold five times with PBS buffer and 5 times with distilled water and allowed to dry partially. Bound peptides were eluted with $10 \mu \mathrm{L}$ acetonitrile/ $\mathrm{H}_{2} \mathrm{O}$ (75/25\%) and collected into a 96-well plate via centrifugation ( $2 \mathrm{~min}, 1500 \mathrm{rpm})$. The resulting mixture of unphosphorylated, phosphorylated and thiophosphorylated peptide was mixed with $6 \mu \mathrm{L}$ matrix solution (75/25/0.1\% acetonitrile/ $\left.\mathrm{H}_{2} \mathrm{O} / \mathrm{TFA}, 10 \mathrm{mg} / \mathrm{mL} \mathrm{CHCA}\right)$ and spotted in triplicate on a stainless steel MALDI target (Applied Biosystems). Spots were analyzed in linear negative mode. Data were processed using a macro provided by Melanie Lin of Applied Biosystems to extract mass and intensity (calculated as area under the isotope cluster curve) into tab-delimited text files.

\section{Solid-Phase Assay}

Assay was performed in 96 -well filter bottom plates. Streptactin-sepharose beads $(6 \mu \mathrm{L})$ were equilibrated with kinase buffer for 1-2 min and excess buffer was removed with a vacuum manifold. Peptide ( $20 \mathrm{nmol}$ ) was added and bound to the beads for $5 \mathrm{~min}$. Beads were washed and additional reagents (kinase buffer as above, ATP, ATP $/ \mathrm{S}$, metal as indicated in plots) and recombinant $\mathrm{Abl}(2.1 \mu \mathrm{g}, \sim 60 \mathrm{pmol})$ were added. Reactions were performed at $30{ }^{\circ} \mathrm{C}$ for $30 \mathrm{~min}$, and samples were quenched, processed and analyzed as above.

\section{Results and Discussion}

We set out to find conditions for using MALDI-TOF to quantify the efficency of thiophosphorylation in the presence of competing phosphorylation. As a model system we chose the tyrosine kinase c-Abl, ${ }^{17}$ for which thiophosphorylation is reported to be undetectable. ${ }^{12,18,19}$ Addition of 'thiophilic' divalent cations to improve Abl thiophosphorylation had not been reported. Mimicking cellular conditions (necessitating the presence of $\mathrm{Mg}^{2+}$ and ATP) was desirable for our overall method development. Typical thiophosphorylation assays do not address detection of competing phosphorylation. MALDI-TOF MS offered direct detection of the ratio of thiophosphorylated to phosphorylated peptide products, allowing us to determine conditions for competitive thiophosphorylation in the presence of ATP. The Abl kinase domain was used in conjunction with an 'optimal' substrate peptide ${ }^{20}$ (in italics) carrying an N-terminal affinity tag (Strep-tag) ${ }^{21}$ (WSHPQFEK)EAIYAAPFAKKK (1) to optimize the conditions for 
thiophosphorylation, and these conditions were applied to selective thiophosphorylation of the peptide substrate 1 by cell extract. To address the inherent spot-to-spot variability in sample crystallization, all experiments were performed in duplicate and each was spotted in triplicate (i.e., six measurements per ratio). Linear mode was used for quantification of peak ratios, because reflectron mode revealed fragmentation of the thiophosphopeptide with loss of $\mathrm{HPO}_{2} \mathrm{~S}$ (see Supporting Information). Negative mode was chosen over positive mode because we find it improves the sensitivity for detection of low-level thiophosphorylation compared to positive mode.

It was important to establish calibration curves to quantify the relationship between phosphorylated and thiophosphorylated peptide. This was accomplished by combining known ratios of the two purified materials and observing the resulting signal intensity ratio in the mass spectrometer (Figure 1). Thio-to phospho-peptide signal ratios were consistently $85 \%$ of the actual ratio in the sample, thus this correction factor was applied to the ratios observed in the rest of the analyses.

We assessed the question of competition between ATP $\gamma$ S and ATP $(1: 1)$ in the conversion of $\mathbf{1}$ using the Abl kinase domain. $\mathrm{Mn}^{2+}, \mathrm{Co}^{2+}$, and $\mathrm{Ni}^{2+}$ were chosen as examples of 'thiophilic' metals previously reported in the literature. In preliminary experiments, $\mathrm{Cu}^{2+}$ and $\mathrm{Hg}^{2+}$ were also investigated but resulted in precipitation problems in the assay. Divalent metal ions $\mathrm{Mg}^{2+}, \mathrm{Mn}^{2+}, \mathrm{Co}^{2+}$, and $\mathrm{Ni}^{2+}(5 \mathrm{mM})$ were used alone and in combination with $\mathrm{Mg}^{2+}\left(10 \mathrm{mM} \mathrm{Mg}^{2+}: 1 \mathrm{mM}\right.$ other $\left.\mathrm{M}^{2+}\right)$. The reactions were performed in solution as described above. Results are summarized in Table 1 . As expected, $\mathrm{Mg}^{2+}$ alone greatly favored phosphorylation. $\mathrm{Mn}^{2+}$ alone resulted in very low overall conversion $(<5 \%)$, but did improve thiophosphorylation (to approximately $1: 1$ ). $\mathrm{Co}^{2+}$ and $\mathrm{Ni}^{2+}$ alone also resulted in minimal conversion to either product. With $\mathrm{Mg}^{2+}$ in the reaction buffer (alone or in combination with another metal), substrate conversion to thio- and/or phospho-peptide was essentially quantitative in $30 \mathrm{~min}$ (with the exception of $\mathrm{Mg}^{2+} / \mathrm{Ni}^{2+}$ which gave only $~ 30 \%$ conversion). The most positive results came from the combination of $\mathrm{Mg}^{2+} / \mathrm{Mn}^{2+}$ : thiophosphorylation was improved 2-fold over $\mathrm{Mg}^{2+}$ alone, and importantly, conversion was quantitative. This 'rescue effect' using low levels of 'thiophilic' divalent metals in combination with $\mathrm{Mg}^{2+}$ is known for ribozymes containing thiophosphate linkages, ${ }^{22-24}$ but has not previously been observed for kinases. The seemingly cooperative effect of $\mathrm{Mg}^{2+}$ and $\mathrm{Mn}^{2+}$ in rescuing thiophosphorylation may result from binary metal cofactor interactions in the kinase active site. ${ }^{25}$ The optimized conditions using $10: 1 \mathrm{Mg}^{2+} / \mathrm{Mn}^{2+}$ allowed us to achieve very high levels of thiophosphorylation in the presence of micromolar levels of ATP (Figure 2). This should be compared to the reports in the literature mentioning the failure of previous attempts to detect thiophosphorylation by Abl kinase. ${ }^{10,16,17}$

Additional characterization of key reactants $\left(\mathrm{Mn}^{2+}\right.$ and ATP $\left./ \mathrm{S}\right)$ and in depth analysis of ATP and ATP $\gamma \mathrm{S}$ competition was carried out in an on-bead assay. 1 was pre-bound to the beads and subjected to the kinase reactions varying the levels of $\mathrm{Mn}^{2+}$ or ATP $\gamma \mathrm{S}$ (up to 48 conditions in duplicate for a total of 96 reactions). The products were analyzed directly by fixing a small amount of beads to the MALDI target with matrix. The matrix solution containing acetonitrile/ $\mathrm{H}_{2} \mathrm{O} /$ TFA served to elute the peptide from the beads. These studies showed that as little as $0.5 \mathrm{mM} \mathrm{Mn}^{2+}$ in the presence of $10 \mathrm{mM} \mathrm{Mg}^{2+}$ promoted selectivity 
for thiophosphorylation, and that using the optimized $\mathrm{Mg} / \mathrm{Mn}$ combination buffer (10:1), a ratio of 10:1 ATP $\gamma$ S to ATP was sufficient to achieve 1:1 ratios of thiophosphorylated to phosphorylated product. Importantly, these reagent levels are within a practical range for use in cell extracts. We demonstrated this using the optimized conditions (described in Figure 2) with K562 chronic myeloid leukemia cell extracts (which overexpress the oncogenic fusion protein Bcr-Abl) to thiophosphorylate $\mathbf{1}$. Specificity was shown using the Bcr-Abl inhibitor Gleevec (Figure 3). Notably, $10 \mathrm{mM} \mathrm{MgCl} 2$ or $1 \mathrm{mM} \mathrm{MnCl}_{2}$ alone did not promote thiophosphorylation in these conditions (Figure 4).

The high-throughput capabilities of this assay will in the future allow rapid, convenient determination of optimal thiophosphorylation conditions for other kinases. The key advantage is the ability to observe both phosphorylation and thiophosphorylation in the same assay. For example, we demonstrated the use of the ATP:ATP $\gamma \mathrm{S}$ competition assay using the catalytic subunit of the serine/threonine kinase PKA. Thiophosphorylation of the substrate peptide LCGRTGRRNSI-NH $\mathrm{NH}_{2}$ (biotinylated on the N-terminus) was carried out according to the solution phase protocol described above. Although PKA was reasonably efficient at thiophosphorylating its substrate even with only $\mathrm{Mg}^{2+}(\sim 10-15 \%$ thiophosphopeptide produced at 1:1 ATP/ATP/S), a mild improvement in thiophosphorylation was gained (15-20\% thiophosphopeptide produced) by using $\mathrm{Co}^{2+}$ in the reaction buffer (Table 2)-however, the reaction proceeded efficiently with $\mathrm{Co}^{2+}$ alone in the buffer and addition of $\mathrm{Mg}^{2+}$ only modestly improved the rate. We are currently screening other kinases in this assay to determine if the thiophosphorylation 'rescue' observed for Abl kinase with $\mathrm{Mg}^{2+} / \mathrm{Mn}^{2+}$ is a general effect for tyrosine kinases or if it is specific to some kinases and not others. Our primary goal is to use these optimized conditions for Abl kinase to investigate thiophosphorylation of endogenous substrates by $\mathrm{Bcr}-\mathrm{Abl}$ in K562 cell extracts, in response to changes in cellular states, with high throughput detection by MALDI-TOF mass spectrometry. The assay described here should facilitate access to thiophosphorylation as a tool for phosphoproteomics in general, but especially for systems such as ours that require optimization of not only the 'thiophilic' cation required for the kinase of interest, but also ATP $/ \mathrm{S}$ competition in the presence of ATP and $\mathrm{Mg}^{2+}$, a feature which will prove crucial for making thiophosphorylation practical for in vivo use.

\section{Supplementary Material}

Refer to Web version on PubMed Central for supplementary material.

\section{Acknowledgment}

We thank Greg Flugum and Don Wolfegher of the proteomics core facility for MALDI-MS training and technical support, and Evan Nair-Gill and Vivian Tien for help with initial assay development. Abl kinase domain was a kind gift from Markus Seeliger and John Kuriyan (UC-Berkeley). Financial support provided by NIH Cardiovascular Pathophysiology training grant T32 HL0723, the University of Chicago NSF MRSEC and R33 CA103235. S.J.K. is a Scholar of the Leukemia and Lymphoma Society.

\section{References}

(1). Hunter T. Signaling-2000 and beyond. Cell. 2000; 100(1):113-127. [PubMed: 10647936] 
(2). Jeong S, Nikiforov TT. Kinase assay based on thiophosphorylation and biotinylation. Biotechniques. 1999; 27(6):1232-1238. [PubMed: 10631503]

(3). Kwon SW, Kim SC, Jaunbergs J, Falck JR, Zhao Y. Selective enrichment of thiophosphorylated polypeptides as a tool for the analysis of protein phosphorylation. Mol. Cell Proteomics. 2003; 2(4):242-247. [PubMed: 12734387]

(4). Sun IY, Allfrey VG. In vivo thiophosphorylation of chromosomal proteins. Recovery and analysis of HeLa histones and derivative phosphopeptides. J. Biol. Chem. 1982; 257(3):1347-1353. [PubMed: 7056720]

(5). Allen JJ, Lazerwith SE, Shokat KM. Bio-orthogonal affinity purification of direct kinase substrates. J. Am. Chem. Soc. 2005; 127(15):5288-5289. [PubMed: 15826144]

(6). Nikiforov TT, Simeonov AM. Application of fluorescence polarization to enzyme assays and single nucleotide polymorphism genotyping: Some recent developments. Comb. Chem. High T. Scr. 2003; 6(3):201-212.

(7). Hiriyanna KT, Baedke D, Baek KH, Forney BA, Kordiyak G, Ingebritsen TS. Thiophosphorylated substrate analogues are potent active site-directed inhibitors of protein-tyrosine phosphatases. Anal. Biochem. 1994; 223(1):51-58. [PubMed: 7718049]

(8). Cassel D, Glaser L. Resistance to phosphatase of thiophosphorylated epidermal growth factor receptor in A431 membranes. Proc. Natl. Acad. Sci. U.S.A. 1982; 79(7):2231-2235. [PubMed: 6285374]

(9). Cassidy P, Hoar PE, Kerrick WG. Irreversible thiophosphorylation and activation of tension in functionally skinned rabbit ileum strips by $\left[{ }^{35}\right.$ S]ATP gamma S. J. Biol. Chem. 1979; 254(21): 11148-11153. [PubMed: 500632]

(10). Grace MR, Walsh CT, Cole PA. Divalent ion effects and insights into the catalytic mechanism of protein tyrosine kinase Csk. Biochemistry. 1997; 36(7):1874-1881. [PubMed: 9048573]

(11). Sondhi D, Xu W, Songyang Z, Eck MJ, Cole PA. Peptide and protein phosphorylation by protein tyrosine kinase Csk: insights into specificity and mechanism. Biochemistry. 1998; 37(1):165172. [PubMed: 9425036]

(12). Zou K, Miller WT, Givens RS, Bayley H. Caged Thiophosphotyrosine Peptides. Angew. Chem. Int. Ed. Engl. 2001; 40(16):3049-3051. [PubMed: 12203645]

(13). Min DH, Su J, Mrksich M. Profiling kinase activities by using a peptide chip and mass spectrometry. Angew Chem. Int. Ed. Engl. 2004; 43(44):5973-5977. [PubMed: 15547909]

(14). Zeller M, Essmann F, Janicke RU, Schulze-Osthoff K, Konig S. A rapid nonradioactive peptide phosphorylation assay. J. Exp. Ther. Oncol. 2003; 3(2):59-61. [PubMed: 12822511]

(15). Houseman BT, Huh JH, Kron SJ, Mrksich M. Peptide chips for the quantitative evaluation of protein kinase activity. Nat. Biotechnol. 2002; 20(3):270-274. [PubMed: 11875428]

(16). Matsumoto H, Kahn ES, Komori N. Nonradioactive phosphopeptide assay by matrix-assisted laser desorption ionization time-of-flight mass spectrometry: Application to calcium/calmodulindependent protein kinase II. Anal. Biochem. 1998; 260(2):188-194. [PubMed: 9657877]

(17). Pendergast AM. The Abl family kinases: Mechanisms of regulation and signaling. Adv. Cancer Res. 2002; 85:51-100. [PubMed: 12374288]

(18). Martin K, Steinberg TH, Cooley LA, Gee KR, Beechem JM, Patton WF. Quantitative analysis of protein phosphorylation status and protein kinase activity on microarrays using a novel fluorescent phosphorylation sensor dye. Proteomics. 2003; 3(7):1244-1255. [PubMed: 12872225]

(19). Martin K, Steinberg TH, Goodman T, Schulenberg B, Kilgore JA, Gee KR, Beechem JM, Patton WF. Strategies and solid-phase formats for the analysis of protein and peptide phosphorylation employing a novel fluorescent phosphorylation sensor dye. Comb. Chem. High T. Scr. 2003; 6(4):331-339.

(20). Songyang Z, Carraway KL 3rd, Eck MJ, Harrison SC, Feldman RA, Mohammadi M, Schlessinger J, Hubbard SR, Smith DP, Eng C. Catalytic specificity of protein-tyrosine kinases is critical for selective signaling. Nature. 1995; 373(6514):536-539. [PubMed: 7845468]

(21). Skerra A, Schmidt TG. Use of the Strep-Tag and streptavidin for detection and purification of recombinant proteins. Methods Enzymol. 2000; 326:271-304. [PubMed: 11036648] 
(22). Shan S, Kravchuk AV, Piccirilli JA, Herschlag D. Defining the catalytic metal ion interactions in the Tetrahymena ribozyme reaction. Biochemistry. 2001; 40(17):5161-5171. [PubMed: 11318638]

(23). Basu S, Strobel SA. Thiophilic metal ion rescue of phosphorothioate interference within the Tetrahymena ribozyme P4-P6 domain. RNA. 1999; 5(11):1399-1407. [PubMed: 10580468]

(24). Cunningham LA, Li J, Lu Y. Spectroscopic evidence for inner-sphere coordination of metal ions to the active site of a hammerhead ribozyme. J. Am. Chem. Soc. 1998; 120(18):4518-4519.

(25). Cheng Y, Zhang Y, McCammon JA. How Does the cAMP-Dependent Protein Kinase Catalyze the Phosphorylation Reaction: An ab Initio QM/MM Study. J. Am. Chem. Soc. 2005; 127:15531562. [PubMed: 15686389] 


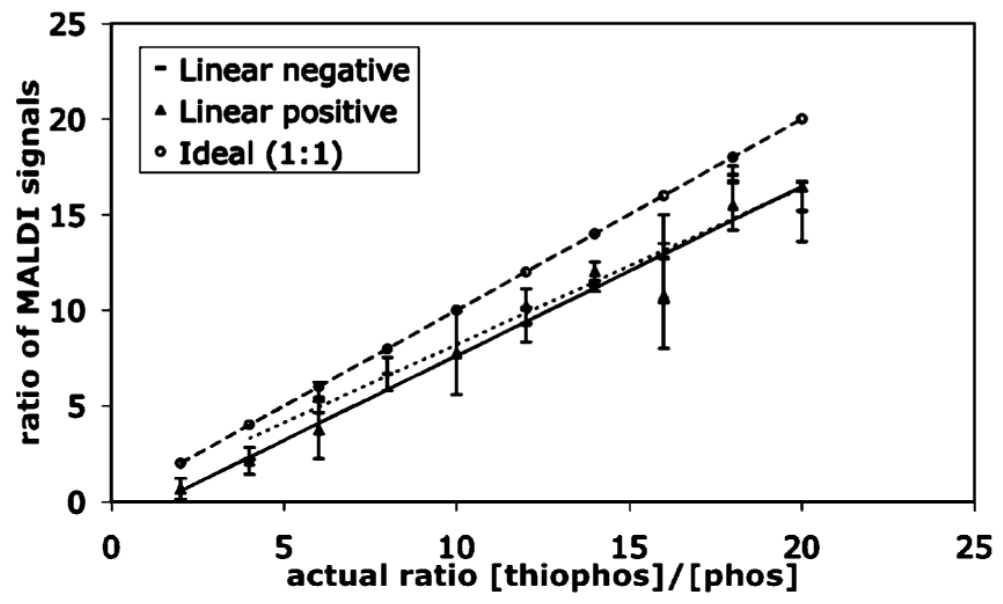

Figure 1.

Calibration curve representing signal intensity ratios of thiophosphopeptide to phosphopeptide in both linear positive and negative modes (calculated as area under the curve) compared to the ideal ratio. 


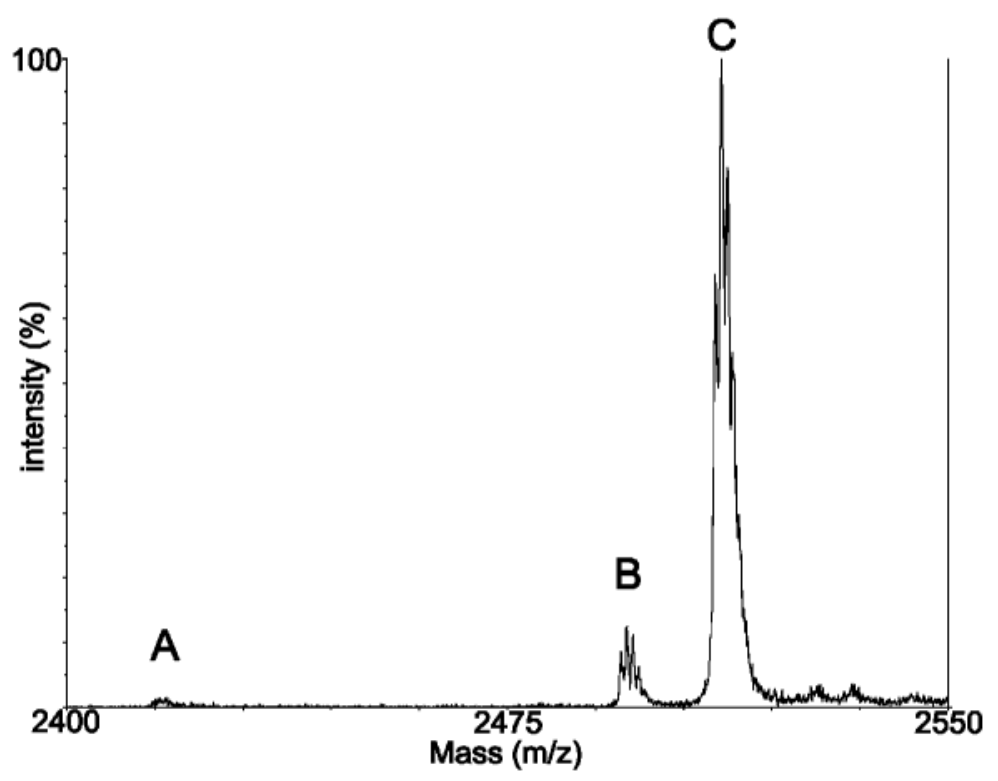

Figure 2.

Optimized thiophosphorylation conditions: ATP $\left(2.5 \mu \mathrm{M}\right.$ ATP $\gamma \mathrm{S}(1 \mathrm{mM}), \mathrm{MgCl}_{2}(10 \mathrm{mM})$, $\mathrm{MnCl}_{2}$ (1 mM). A: unphosphorylated; B: phosphorylated; C: thiophosphorylated. 

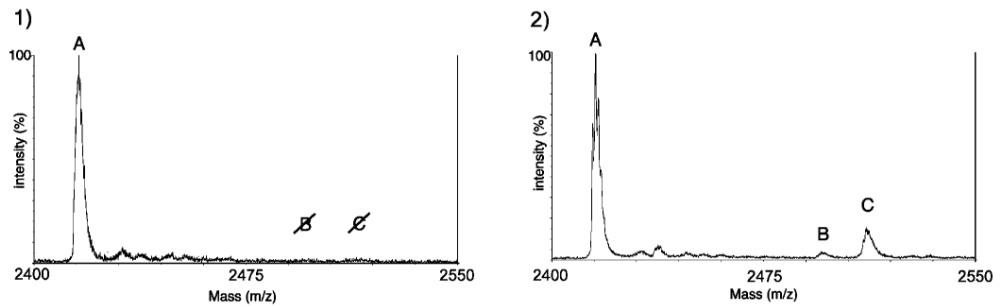

Figure 3.

Thiophosphorylation of 1 by Bcr-Abl in K562 cell extracts (1) with and (2) without inhibitor. A: unphosphorylated; B: phosphorylated; C: thiophosphorylated. 


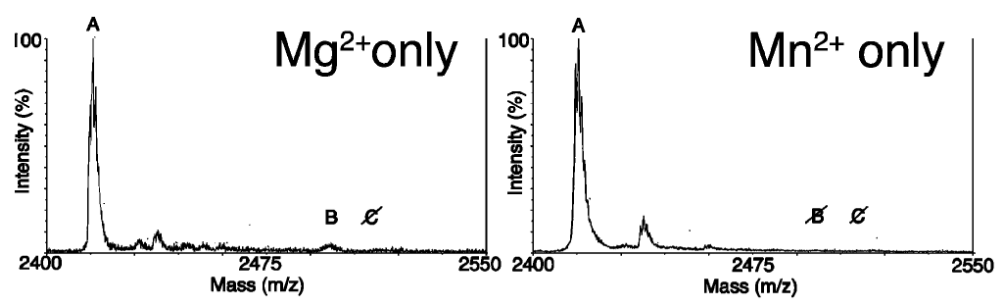

Figure 4.

Thiophosphorylation of 1 by Bcr-Abl in K562 cell extracts with $\mathrm{Mg}^{2+}$ and $\mathrm{Mn}^{2+}$ alone. No thiophosphorylation is observed with $\mathrm{Mg}^{2+}$ alone, and no conversion is observed for $\mathrm{Mn}^{2+}$ alone. A: unphosphorylated; B: phosphorylated; C: thiophosphorylated. 
Table 1

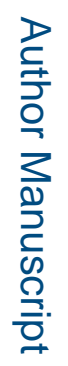

Addition of $\mathrm{Mn}^{2+}$ with $\mathrm{Mg}^{2+}$ Resulted in a 2-3-Fold Improvement in Thiophosphorylation by Abl Kinase Domain Compared to $\mathrm{Mg}^{2+}$ Alone

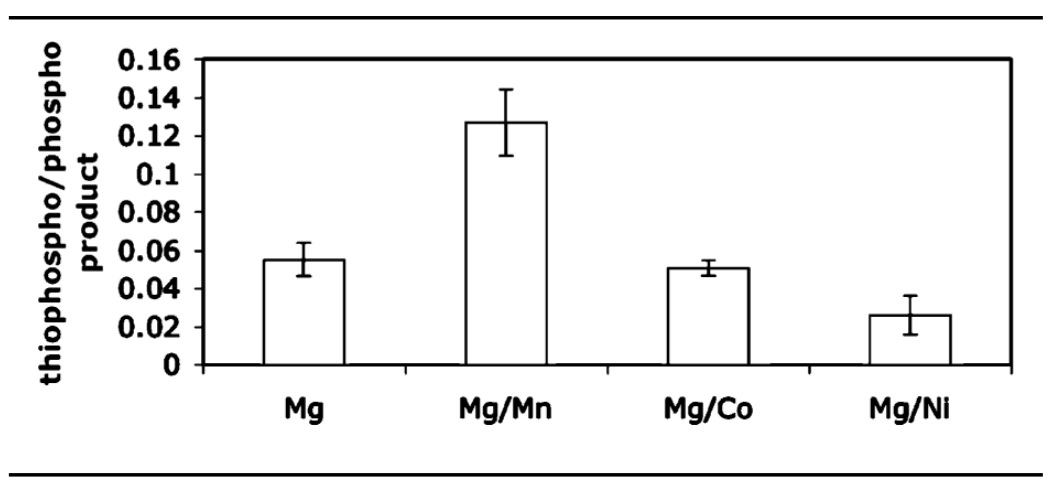

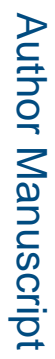

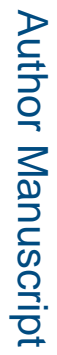

J Proteome Res. Author manuscript; available in PMC 2015 September 14. 


\section{Table 2}

$\mathrm{Co}^{2+}$ Provided a Slight Increase in Thiophosphorylation by PKA, However Conversion Was Quantitative with and without $\mathrm{Mg}^{2+}$

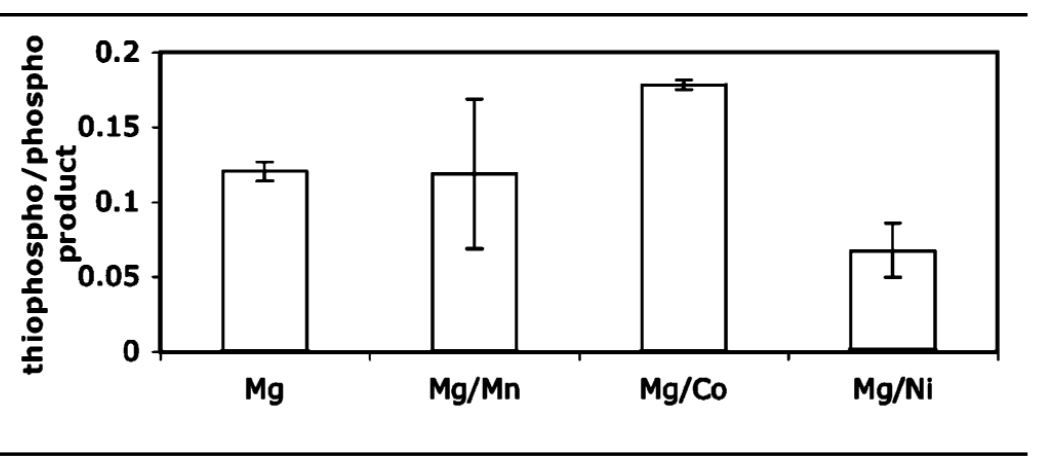

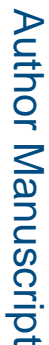

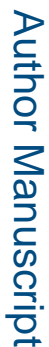

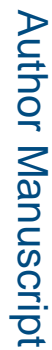

